\title{
Adaptation of the Athletic Identity Measurement Scale (AIMS-Plus) for the Portuguese Population
}

\author{
Adaptação da Escala de Identidade Atlética (AIMS-plus) \\ para a População Portuguesa
}

\author{
Túlia Maia Cabrita ${ }^{a}$, António Boleto Rosado*, $a$, Teresa Oliveira Leite ${ }^{b}$, Paulo Malico Sousa ${ }^{c}$ \\ ${ }^{a}$ Universidade de Lisboa, Lisboa, Distrito de Lisboa, Portugal, \\ ${ }^{b}$ Universidade Lusiada de Lisboa, Lisboa, Distrito de Lisboa, Portugal \\ \& Instituto Superior de Ciências Educativas, Lisboa, Distrito de Lisboa, Portugal
}

\begin{abstract}
Athletic Identity may be defined as being the degree of importance, strength and exclusivity that is attached to the athlete's role which is maintained by him/herself and his/her context (Cieslak, 2004). In this study, using a confirmatory factor analysis, the measure of Athletic Identity (AIMS-plus) was examined. A total of 650 athletes completed the AIMS-plus. The psychometric features of the original scale were replicated to the Portuguese population. Validity and reliability were positive. AIMS-plus and AIMS were high correlated suggesting that both scales derive from similar athletic identity concepts. These results suggest that AIMS-plus seems to be an acceptable psychometric instrument and a good measure to be explored in research and intervention for athletic identity. It's also recommended further studies of the psychometric characteristics.

Keywords: Athletic identity, multidimensional, cross-cultural validation.
\end{abstract}

\begin{abstract}
Resumo
Identidade Atlética pode ser definida como o grau de importância, força e exclusividade vinculada ao papel de atleta que é mantida pelo contexto e pelo próprio (Cieslak, 2004). No presente estudo, através de uma análise factorial confirmatória, foi examinada a medida de identidade atlética - AIMS-plus utilizando um total de 650 atletas. Replicaram-se as características psicométricas da escala original para a população portuguesa e verificou-se que a validade e fidelidade são adequadas. O AIMS-plus e o AIMS aparecem correlacionados de forma elevada e positiva o que confirma a derivação comum do mesmo conceito de Identidade Atlética. Os resultados sugerem que o AIMS-plus apresenta capacidades psicométricas aceitáveis e uma boa medida a ser explorada pela investigação e a ser utilizada na intervenção com atletas. É recomendada a continuação da exploração das características psicométricas. Palavras-chave: Identidade atlética, multidimensional, validação transcultural.
\end{abstract}

The process of athletes' identification to sports role often influences one's personal experiences, interpersonal relationships and the consolidation of one's involvement in sports activity (Cornelius, 1995), quite often at the expense

* Mailing address: Faculdade de Motricidade Humana, Universidade de Lisboa, Estrada da Costa, Cruz Quebrada, Dafundo, Portugal 1499-002. E-mail: arosado@ fmh.utl.pt.

Agradecemos ao Professor Doutor Britton Brewer e ao Professor Doutor Thomas Cieslak a autorização para a adaptação cultural das escalas AIMS e AIMS-plus.

Agradecemos, também, a Richard Maurer, nativo da língua inglesa pela precisosa ajuda ao verificar e ajustar o documento para a língua inglesa.

Esta pesquisa foi suportada pela Fundação para a Ciência e Tecnologia do Ministério da Ciência e do Ensino Superior do governo português (FCT) com a ref. SFRH/ $\mathrm{BD} / 41374 / 2007$

Este manuscrito é parte resultante do Doutoramento de Túlia Maia Cabrita orientado pelo Professor Doutor António Rosado na Faculdade de Motricidade Humana

- Universidade Técnica de Lisboa. of other personal and social experiences (Brewer, 1993). This very process of identification (athletic identity), which is acknowledged by the athlete himself, valued in his environment and appreciated by his significant others, constitutes quite often, the whole of the athlete's self-identity (Balague, 1999).

Research regarding the concept of athletic identity (AI) has shown that having a strong identification as an athlete can have as much of a negative impact as it has a positive one in the life of athletes. Those athletes with a strong athletic identity seem to have a stronger sense of self-identity, more social interactions and they exhibit high levels of self-confidence. They also report more positive experiences than those athletes with lower levels of athletic identity (Brewer, Van Raalte, \& Linder, 1993; LamontMills \& Christensen, 2006; Wiechman \& William, 1997). However, this high level of AI may lead to an overinvolvement with sports practice, emotional difficulties associated with career choice, humour disorders, substance abuse, 
unrealistic expectations regarding a sports related career and a lack of preparation for life and work outside of the sports world (Grove, Lavalle, \& Gordon, 1997; Horton \& Mack, 2000; Hurst, Hale, Smith, \& Collins, 2000). The intensity of AI varies in association with past relationship to sports and current athletic experiences, as well as the athlete's personal experiences with athletic failures and successes (Horton \& Mack, 2000).

Several authors have been trying to understand this dimension of the identity concept since the 90 's (Brewer, 1993; Horton \& Mack, 2000; Hurst et al., 2000; Martin, Mushet, \& Smith, 1995; Smith, Hale, \& Collins, 1998). The first publications consider AI as a unidimensional construct defined it as the extent to which an individual identifies him/herself with the role of the athlete (Brewer, Van Raalte, et al., 1993). Following this idea Brewer and Cornelius (2001), proposed a multidimensional model for AI, based on a multidimensional perspective of selfconcept (Marsh, 1990) and the conceptualization that AI is a cognitive structure that interprets the involvement of the subject in the sport context and the implications that has for himself. These cognitive self-evaluations are influenced by significant others (coaches, colleagues, parents, etc.) and determine both the athlete's choice of priorities in life and his/her negative cognitions about sports performance (Brewer, Van Raalte, et al., 1993). This idea results in the conceptualization of AI expressed in 3 dimensions - social identity, exclusivity and negative affectivity. This model was widely used and a scale was developed - the Athletic Identity Measurement Scale (AIMS), which was adapted to several international populations.

Nevertheless, some critiques have been made to the AIMS, namely, the fact that, AI being of one of several dimensions of identity, the model didn't sufficiently portray all the characteristics of the general concept of identity. In other words, it favors the private dimension of identity (Nasco \& Webb, 2006) and does not rely on the structural identity theory. That is, does not examine with enough depth the role of society and groups (public or external dimension) or the interpretation and evaluation of the self in its identities (internal dimension or private; Cieslak, 2004). Several other studies also have emphasized the need to expand the AIMS (Anderson, 2004; Brewer \& Cornelius, 2001; Brewer, Cornelius, Stephan, \& Van Raalte, 2010; Groff \& Zabriskie, 2006; Hale, James, \& Stambulova, 1999; Martin, Mushet, \& Eklund, 1997; Mastean, Tusak, \& Faganel, 2006; Visek, Hurst, Maxwell, \& Watson, 2008) to include other characteristics of the concept of identity and in doing so, turning athletic identity assessment more complete and with a stronger factorial structure.

Those critiques resulted in the creation of some AI measurement scales such as the PPAIS - Public-Private Athletic Identity Scale (Nasco \&Webb, 2006; Shapiro \& Martin, 2010; Webb, Nasco, Riley, \& Headrick, 1998), the AIMS-Plus (Cieslak, 2004; Cieslak, Fink, \& Pastore, 2005; Delgado, Stanford, \& Cieslak, 2005; Jun, 2008; Richard, 2007; Schmid, Adams, \& Cheng, 2009), and the AIQ-Ath- letic Identity Questionnaire (Anderson, 2004; Anderson \& Coleman, 2008; Anderson, Louise, Zhang, Coleman, \& Chang, 2009; Anderson, Louise, Zhang, Coleman, \& Chang, 2011; Anderson, Mâsse, \& Hergenroeder, 2007).

This study aims validating the AIMS-plus for the Portuguese population. This scale integrates both private and public dimensions of identity (as it was noted by Nasco \& Webb, 2006) and it relies on conceptual models of identity such as the structural theory of identity (Stryker, 1980) and the cognitive theory of identity (Burke, 1991). This means that, based on the assumptins that $\mathrm{AI}$ is one of the identities of the self, AIMS-plus explains how social structures (public dimension and structural theory - external component) and self-assessment (private dimension and cognitive theory identity - internal component) affect the structure of the self and social behavior of the athlete. Therefore, these two factors (internal and external component) play a role in the socialization process that contributes to the formation, maintenance and abandonment of identities as IA (Cieslak, 2004; Cieslak et al., 2005). Furthermore, it values the role of the athlete and the environment in keeping the levels of athletic identity.

O AIMS-plus is based on the definition of athletic identity as being the degree of importance, strength and exclusivity that is attached to the athlete's role that is maintained by the athlete himself and his/her context (Cieslak, 2004; Cieslak et al., 2005). Such definition refers to a theoretical model of athletic identity which includes two major supporting factors: external and internal components influencing the formation of the self and social behavior of the athlete.

The internal components includes, evaluation and interpretation of self and is identities and have consequences on sporting behavior. This dimension is represented in three dimensions, the self identity, positive affectivity and negative affectivity. The external component involves the influence of external factors (eg family, friends, coaches, teachers, media, etc.) upon the subject and in the establishment of his priorities, and it is explained by dimensions: social identity and exclusivity.

The 5 dimensions of this concept (AI) are defined as follows: self Identity (SI - level of the individual's personal awareness of his/her role as an athlete), positive affectivity (PA - the degree to which a person feels good or is encouraged by the results of his sports' participation), and negative affectivity (NA - the degree to which a person feels bad or depressed in response to unwanted results in his/her sports participation), social identity (SI - level of social awareness of his/her role as an athlete, and exclusivity (EX - the importance that the athlete's role acquires in relation to other day-to-day activities; Cieslak, 2004).

The importance of developing a measurement of AI psychometrically valid and reliable - integrating both factors influencing with identity formation and that relate AI with the significant sports events, has led us to study the psychometric properties of the AIMS-plus in the universe of Portuguese athletes. More specifically, it is expected to 
Cabrita, T. M., Rosado, A. B., Leite, T. O., Sousa, P. M. (2014). Adaptation of the Athletic Identity Measurement Scale (AIMS-Plus) for the Portuguese Population.

replicate, in Portuguese results, the factor structure of the AIMS-plus as it was proposed in the original study. Also, into a more refined analysis, tested the model that adjusted at the item level; determine the internal consistency and convergent validity of AIMS-plus; test the invariance of the structure with a cross-validations strategy; and verify if AIMS-plus and its sub-scales show positive significant correlations with another measure of AI.

\section{Method}

\section{Participants}

A total of 650 athletes filled out our questionnaires (233 female, 417 male). The participants could be distributed throughout a range of sports modalities (futsal, basketball, hockey, handball, rugby, soccer, volleyball, gymnastics, fencing, judo, swimming, modern pentathlon and triathlon), with an average age of $20.23(M=20.23$, $S D=5.8)$, belonging to a range of competition categories (5.1\% initiates, $13.1 \%$ juveniles, $36.3 \%$ juniors, 45.5 $\%$ seniors), from two different competition levels (325 competition and 325 high-level competition)

\section{Procedures}

The questionnaires were administered by the coaches, who were contacted by the researchers and instructed on the procedures and rules of administration of such questionnaires. Coaches granted permission to distribute the survey and participants were given an informed consent form to read. Participants were also assured that information gathered would remain confidential and would only be used for the purposes of the project. Afterwards, the surveys were distributed and the participants were given brief instructions on how to complete them. Following the completion of the surveys, all participants were debriefed. The procedures complied with all articles of the Code of Ethics for Research, issued by the University (Faculdade de Motricidade Humana, Universidade Técnica de Lisboa).

\section{Measures}

The participants were asked to fill out a demographic information form, the AIMS questionnaire and the AIMSplus questionnaire.

AIMS-plus (Athletic Identity Measurement Scale plus). The AIMS-plus was created by Cieslak (2004), based on the AIMS (Brewer \& Cornelius, 2001), the Sport Identities Index (SII; Curry \& Weaner, 1987), the identity structural theory (Stryker, 1980) and the cognitive identity theory (Burke, 1991). In order to carry through this adaptation, the author used qualitative methods (a panel of experts was used to assure content and face validity), as well as quantitative methods (exploratory factor analysis and confirmation factor analysis).

The AIMS-plus is a self-report questionnaire with 22 items and a likert-scale model of response ranging from 0 to $100(0=$ totally disagree; $100=$ totally agree $)$. The time of administration ranges from 5 to 10 minutes.
The items are distributed among two major categories: internal and external identity components. These categories, grouped in different dimensions, are comprised by items that represent the essence of each characteristic of identity. The internal components sub-scale is composed by 3 dimension: (a) self-identity - objectifying the items that capture the self-referential cognitions that form a selfassessment and own athlete interpretation (SI - items 1, 2, 13 and 21); (b) positive affectivity - combining items that self-evaluate and interpret the positive experiences of involvement with sport (PA - items 10, 15, 16 and 22); and (c) negative affectivity - showing the evaluation and interpretation that the athlete makes of his performance as poor and how can this have a negative impact on is life (NA - items 7, 9, 12 and 18). The external component is composed by 2 dimensions: (a) social identity - composed by items that capture the ideas present in the athlete regarding their social identity (SI - items 3, 6, 11, 14 and 19); and (b) exclusivity - items that assess the importance of sport for the athlete and the amount of time spent in sport when compared with other areas of life (EX - items 4, 5, 8,17 and 20).

The athletic identity score is obtained by calculating the average score between the sum of the internal components item values and the sum of the external item values, but a partial analysis can also be achieved with the five dimensions. Despite the fact that in its original version the scale had good reliability coefficients (test-retest), good correlations among the various factors and good content validity, the first confirmation factorial analysis resulting model was poor (Cieslak, 2004). Subsequent studies have confirmed and demonstrated the good factor structure of the model (Cieslak et al., 2005).

Byrne (2010) argues that "assessment of model adequacy must be based on multiple criteria that take into account theoretical, statistical, and practical considerations". (p. 84). If we take into consideration the strong theoretical model that supports the AIMS-plus, it's good results in terms of content validity, the high rates of internal consistency and its potential to become an excellent application for the psychologist's practice and for the researcher in the area of identity, we can aim, with the present study, to validate this instrument for the Portuguese athletes population.

AIMS (Athletic Identity Measurement Scale). The AIMS was developed by Brewer and Cornelius (2001) and it is widely used in Athletic Identity research. Its purpose is to measure levels of athletic identity. It is composed by 7 items with a 7-point Likert scale response format, varying from 1 (strongly disagree) to 7 (strongly agree), producing a total sum AI score. The AIMS authors propose a multidimensional model for measuring athletic identity which is composed by three subscales: social identity (SC - items 1, 2 and 3), exclusivity (EX - items 4 and 5) and negative affectivity (NA - items 6 and 7; Brewer, Boin, \& Petitpas, 1993).

The psychometric properties of the AIMS have shown a factorial structure with acceptable fit indexes and a high 
internal consistency index test-retest reability over one-week period (Brewer \& Cornelius, 2001).

\section{AIMS-plus and AIMS Translation Procedures}

Once approval was obtained from the original scales' authors, standard procedures were followed in order to adapt the scales to the cultural context in which they were going to be used (Hambleton, 1994; Hambleton \& Kanjee, 1995). The process of translation and back-translation was carried out by one official English-Portuguese translator and three psychologists who specialized in sports psychology and who had previous knowledge of psychological instrument development. The researchers put all their efforts into securing semantic, idiomatic and conceptual equivalency, as well as all the other cultural adjustments, resolving the discrepancies between the two versions and agreeing upon a final writing of the items' contents.

The final versions of these scales were submitted to a small group of participants $(n=15)$, with similar demographic profiles to the study sample. For this application, athletes were interviewed, individually and in a group format, in order to check the adequacy and clarity of the instructions, the possible interpretation of the items' contents and the format of the questionnaire.

A pilot study was also conducted (Cabrita, Rosado, \& Malico, 2007) with 158 athletes, which allowed for adjusting the wording of the items to the sports practicing population, as well as a pre-test to the factorial structure of the scale.

\section{Statistical Analysis}

A confirmatory factorial analysis of the data was tested in two steps, in order to look for the most suitable model.

Analyses were conducted with SPSS 20 and AMOS 19 software (Arbuckle, 2009). Preliminary analyses consisted of confirmatory factor analysis (CFA). CFA is a common method used to evaluate measure instruments as expected by a pre-established theory (Byrne, 2010). Following the theoretical principles of the model of athletic identity (Cieslak, 2004), its factor structure was evaluated with the CFA using the AMOS 19 software. The maximum likelihood (ML) method was used. For each latent variable, lambda was fixed to 1 for the first observed indicator, as were all error weights. All other parameters were freely estimated. Following discovery of unsatisfactory fit, modification indices and standardized estimates were consulted to evaluate alternative models or possible item deletions.

Several goodness-of-fit indexes were selected to evaluate the model's adequacy. Marsh, Balla, and McDonald (1988) proposed adjustment indexes that are (a) relatively independent of the sample size, (b) consistent in the evaluation of several types of models, and (c) easy for interpretation. In this respect, the CFI (comparative fit index), the PCFI (parsimony comparative fit index) and the RMSEA (root mean square error of approximation) were used. CFI values equal or higher than .90 show good adjustment (Carlson \& Mulaik, 1993). A RMSEA value lower than .05 indicates good adjustment, but higher than .10 is considered unacceptable (Browne \& Cudeck, 1993). Chi-square test $(\chi)$ and $\chi^{2} / d f$ were also used, considering that these indicators are sensitive to sample size (Gerbin \& Anderson, 1985).

Internal reliabilities and convergent validity were also calculated (Fornell \& Larcker, 1981; Hair, Anderson, Tatham, \& Black, 2009)

In order to identify for AIMS-plus' factorial invariance, we use cross-validation procedures with strategy of multi-group analysis (Brown, 2006; Davey, 2010; Schumaker \& Lomax, 2004).

In order to facilitate reading and interpretation of statistical results, the AIMS-Plus response scale was converted from $0-100$ to $0-10$ values.

\section{Results}

\section{Descriptive Analyses of the AIMS-Plus Scales}

Table 1 reports the AIMS-plus scales descriptive statistics. The mean values of the scales and the AI standard deviations seem to show that all the aspects of athletic identity were felt relatively frequently by participants. All the AIMS-plus dimensions present acceptable scores of skewness e kurtosis (between -2 e 2) suggesting the normality univariance of the data collected (Kollo, 2008).

Table 1

Descriptive Statistics for AIMS-plus (N=650)

\begin{tabular}{ccccccc}
\hline & $M$ & $S D$ & Min & Max & Skewness & Kurtosis \\
\hline Athletic Identity & 6.9 & 1.6 & 0 & 10 & -.24 & -.70 \\
Social Identity & 6.2 & 1.6 & 0 & 10 & -.27 & -.07 \\
Exclusivity & 5.9 & 1.8 & 0 & 10 & -.05 & -.49 \\
Self-Identity & 7.1 & 2.1 & 0 & 10 & -.32 & -.39 \\
Positive affectivity & 7.7 & 1.5 & 0 & 10 & -.55 & -.56 \\
Negative affectivity & 7.2 & 1.6 & 0 & 10 & -.54 & -.49 \\
\hline
\end{tabular}

Note. $M=$ mean; $S D=$ standard deviation; $M i n=\operatorname{minim} ; \operatorname{Max}=\operatorname{maxim}$. 
Cabrita, T. M., Rosado, A. B., Leite, T. O., Sousa, P. M. (2014). Adaptation of the Athletic Identity Measurement Scale (AIMS-Plus) for the Portuguese Population.

\section{Confirmatory Factor Analytic Strategy}

The AIMS-plus presents as a scale based on a theoretical model with factorial validity (Cieslak, 2004; Cieslak et al., 2005). Taking into account that the aim of this study was to verify its adaptation to Portuguese athletes, it becomes useful to opt for a strategy of confirmatory factor analysis (CFA). The CFA appears as most advantageous in the context of comparing models (as suggested by Joreskog, 1993).

In order to confirm the factorial structure of the AIMSplus' model, an analysis of confirmatory factorial validity was conducted, using Cieslak's AI model (2004). Given that this is a 3rd order model we chose a two-step confirmatory strategy (as suggested by Byrne, 2010; Kline, 2011; Schumaker \& Lomax, 2004). Initially a test was conducted on the $2^{\text {nd }}$ order model (Model 1 and 2: AI represented in its five dimensions, SC, EX, SI, PA and NA -Table 2) and after in a second step we tested the model $3^{\text {rd }}$ Order
(Model 3: AI organized into two major categories (internal and external factors) with 5 factors associated with them - Table 2).

The results of the analysis to model 1 (Table 2) reveal adjustment indexes that were poor, therefore, the factorial structure was study and all scale items that showed unacceptable factor loadings were removed. This process resulted in the removal of items 3, 7, 8, 13, 17, 19 and 21 from the original AIMS-plus. All other items were kept in their original dimensions, reducing from 22 to 15 items the model.

Another analysis was conducted with a 5-factor and 15-item model, showing that in model 2 (Table 2) the fit indexes were quite acceptable. Figure 1 shows the secondorder model factor of the AIMS-plus. Most of the factor loadings were high, with loadings above .70 , except for item 11 (.63), item 14 (.68), item 4 (.64) e item 5 (.67). All the factor loadings are significant $(p<.05)$.

Table 2

Goodness of Fit Indices for the Model of the Confirmatory Factor Analyses Evolution Process of the AIMS-plus

\begin{tabular}{cccccccccc}
\hline CFA Steps & AIMS-Plus Models & $N$ & $\chi^{2}(d f)$ & $\chi^{2} d f$ & CFI & PCFI & GFI & PGFI & RMSEA \\
\hline $\begin{array}{c}\text { Model 1-AIMS-plus } \\
\text { (22 items) }\end{array}$ & 650 & 1460.036 & 7.337 & .862 & .743 & .801 & .630 & .099 \\
$2^{\text {nd }}$ Order Model & $\begin{array}{c}\text { Model 2-AIMS - plus } \\
(15 \text { items })\end{array}$ & 650 & 387.714 & 4.616 & .952 & .762 & .927 & .649 & .075 \\
$\begin{array}{c}2 \text { Step } \\
\text { Model 3 - AIMS-plus } \\
(15 \text { items })\end{array}$ & 650 & 754.150 & 8.769 & .895 & .733 & .892 & .640 & .109 \\
\hline
\end{tabular}

Note. $N=$ number of participants; $\chi^{2}=$ chi-square; $d f=$ degrees of freedom; $\mathrm{CFI}=$ comparative fit index; $\mathrm{PCFI}=$ parsimony comparative fit index; GFI= goodness of fit index; PGFI= parsimony goodness of fit index; RMSEA = root mean square error of approximation.

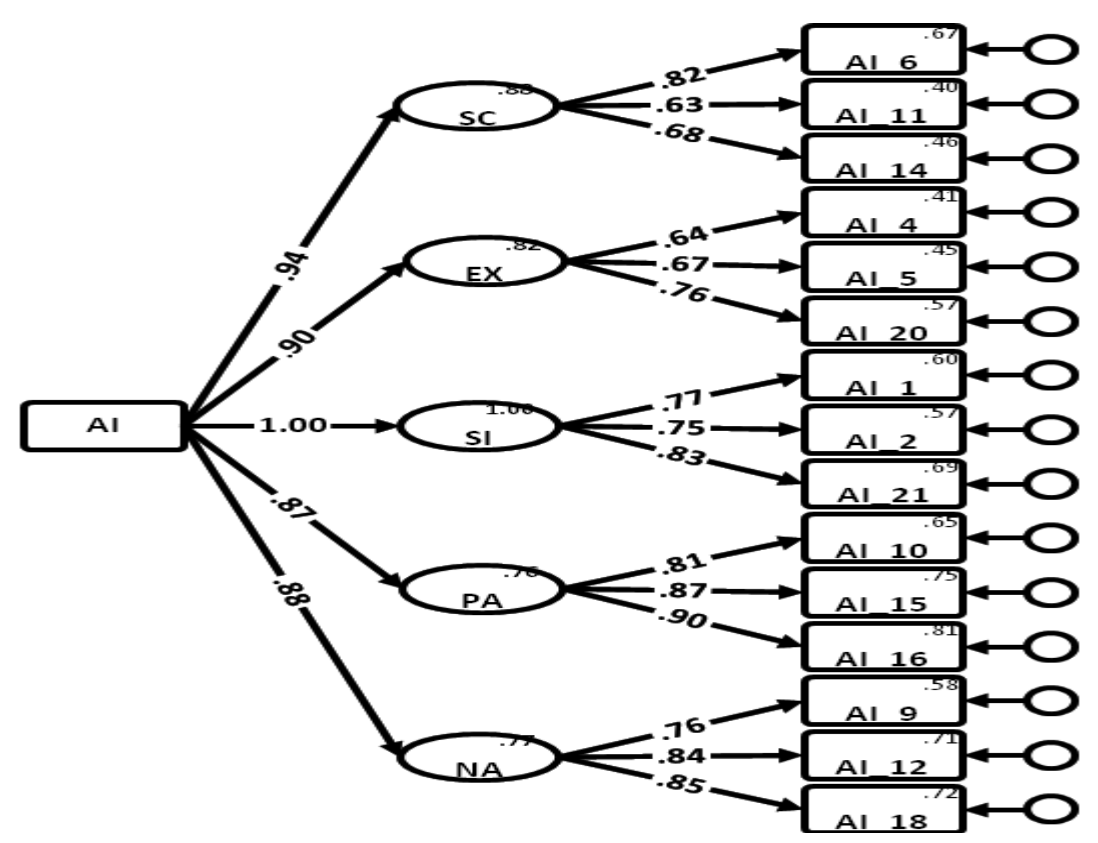

Figure 1. Model of Aims-plus with factor loadings $(n=650)$. 
When the AIMS-plus $3^{\text {rd }}$ Order model was tested regarding its components - internal and external (Model 3 - Table 2), model 3 was not adequately adjusting to the data, which can be explained by the high correlation between AI and first-order factors (Figure 1), making it difficult to establish a third order model, as it was proposed by Cieslak (2004).

In order to test AIMS-plus' internal consistency (reliability), we followed the recommendations of Fornell e
Larcker (1981) to calculate reliability composite (RC), in which it is considered that values $\geq .7$ indicates a proper value of RC. In order to assess the convergent validity, the average variance extracted (AVE) was utilized, whereby values of $\mathrm{AVE} \geq .5$ are appropriate indicators of convergent validity (Hair et al., 2009). Table 3 shows that both values are within acceptable levels of RC and AVE, which suggests that a factorial structure may adequately measure and explain the construct of athletic identity.

Table 3

Composite Reliability and Convergent Validity for AIMS-Plus ( $n=650)$

Athletic Identity Social Identity Exclusivity Self-identity Negative affectivity Positive affectivity

\begin{tabular}{|c|c|c|c|c|c|c|}
\hline $\mathrm{RC}$ & .86 & .75 & .73 & .83 & .86 & .84 \\
\hline AVE & .55 & .51 & .48 & .62 & .67 & .74 \\
\hline
\end{tabular}

Note. $\mathrm{RC}$ : reliability composite; $\mathrm{AVE}=$ average variance extracted convergent validity.

To study the adequacy of model replication cross-validation procedures were used (Schumaker \& Lomax, 2004), more specifically, a cross validation technique of split-half, consisting on a randomly split of the original sample (Davey, 2010; Schumaker \& Lomax, 2004), and then a technique of parameter-invariance to verify the equivalence between the two groups. According to Brown (2006) examining the concordance of the structural parameters can be done by a multi-groups analysis.

Thus, using the SPSS 20, performed a randomly dividing of the sample, which allowed us to have two equivalent groups in their characteristics $\left(\mathrm{n}_{\text {testing sample }}=328\right.$; $\mathrm{n}_{\text {validation sample }}=322$ ), followed by application of model-plus AIMS found (Figure 1) to each of the groups. Then we study the equivalence between the parameters of the two groups by checking its invariance, using for this multi-groups analysis.

The results of this procedures of multi-groups analysis are shown in Table 4. The fit of the scale for the testing and validation samples (Model 1 - Table 4) was satisfactory, as well as for the models with constrained factor loadings (Model 2 - Table 4) and constrained variances/ co-variances (Model 3 - Table 4). The $\chi^{2}$ statistic showed no significant differences between Model 1 (Table 4) and Model 2 [ $\chi^{2} \operatorname{dif}(10)=8.44 ; p=.39$; Table 4], and also no significant differences between Model 1 and Model $3\left[\chi^{2}\right.$ dif (14) $=13.68 ; p=.47$; Table 4]. Thus, the results demonstrated the model's invariance in both samples, indicating that the factorial structure of the scale was stable in two independent samples.

Table 4

Results of the Multi-Group Analysis across the Unconstrained Model and the Constrained Models of the AIMS-plus (Testing sample: $n=328$; Validation sample: $n=322$ )

\begin{tabular}{lcccccccccc}
\hline Multi-group models & $\chi^{2}$ & $d f$ & $\Delta \chi^{2}$ & $\Delta d f$ & $p$ & CFI & GFI & PCFI & PGFI & RMSEA \\
\hline Model 1 & 470.39 & 166 & --- & --- & --- & .95 & .91 & .75 & .63 & .05 \\
Model 2 & 478.86 & 176 & 8.44 & 10 & .39 & .95 & .91 & .80 & .66 & .05 \\
Model 3 & 484.07 & 180 & 13.68 & 14 & .47 & .95 & .91 & .87 & .68 & .05 \\
\hline
\end{tabular}

Note. $\chi^{2}=$ chi-square; $d f=$ degrees of freedom; $\mathrm{CFI}=$ comparative fit index; $\mathrm{PCFI}=$ parsimony comparative fit index; GFI= goodness of fit index; PGFI= parsimony goodness of fit index; RMSEA = root mean square error of approximation; $p=p$-value.

Besides the factorial structure of the AIMS-plus, it is also important to examine its concurrent validity. To further document AIMS-plus validity evidence, associations with another criterion measure of the same construct were identified. Consequently, inter-scale correlations were as- sessed between the AIMS-plus factors and one other AI scale, namely, the AIMS measure, an additional instrument that was administered simultaneously.

Much like for the AIMS-plus, a first analysis was conducted with AIMS in order to study its psychometric 
Cabrita, T. M., Rosado, A. B., Leite, T. O., Sousa, P. M. (2014). Adaptation of the Athletic Identity Measurement Scale (AIMS-Plus) for the Portuguese Population.

properties and acceptable levels of adjustment were found: $\chi^{2}(d f)=5.301, \mathrm{GFI}=.975, \mathrm{IFI}=.973, \mathrm{TLI}=.948, \mathrm{CFI}=$ .973 and $\mathrm{RMSEA}=.081$. The reliability composite $(\mathrm{AI}=$ $.97, \mathrm{SC}=.75, \mathrm{EX}=.78$ and $\mathrm{NA}=.69)$ and the convergent validity values were also acceptable $(\mathrm{AI}=.78, \mathrm{SC}=.51$, $\mathrm{EX}=.65$ and $\mathrm{NA}=.52$ ).
In conclusion, the results of the inter-correlation between the two AIMS-plus and AIMS scales (Table 5) show that both scales are significantly and positively correlated with each other, with correlation coefficients higher than .70 , thus confirming the proposed hypothesis of concurrent validity and reinforcing the psychometric relevance of the Portuguese version of the AIMS-plus instrument.

Table 5

Correlations between AIMS-plus and AIMS for Global AI and Scales $(n=650)$

\begin{tabular}{ccccc}
\hline AIMS-plus & AIMS & SC & EX & NA \\
\hline AI & & & $.803^{* *}$ & $.918^{* *}$ \\
SC & $.936^{* *}$ & $.935^{* *}$ & $.803^{* *}$ & $.917^{*}$ \\
EX & $.936^{* *}$ & $.935^{* *}$ & $.877^{* *}$ & $.892^{* *}$ \\
SI & $.921^{* *}$ & $.914^{* *}$ & $.803^{* *}$ & $.917^{* *}$ \\
PA & $.936^{* *}$ & $.935^{* *}$ & $.676^{* *}$ & $.833^{* *}$ \\
NA & $.832^{* *}$ & $.830^{* *}$ & $.733^{* *}$ & $.913^{* *}$ \\
\hline
\end{tabular}

Note. $\mathrm{AI}=$ Athletic Identity; $\mathrm{SC}=$ Social Identity; EX = Exclusivity; SI = Self-Identity; PA = Positive Affectivity; NA = Negative Affectivity.

* Significant correlation at $\alpha>.05 ; * *$ Significant correlation at $\alpha>.001$.

\section{Discussion}

The construct of Athletic Identity (AI) has been widely tested and used within the North American population, but it is yet to be explored within the Portuguese population. Therefore, the main purpose of this study was a cross-cultural adaptation of the AIMS-plus scale (Cieslak, 2004) to be used with Portuguese athletes.

The confirmatory factorial analysis performed on the AIMS-plus replicates the psychometrics features that were determined for the original English questionnaire and provides us with evidence of the AIMS-plus' validity and reliability.

Although the original structure of the scale was confirmed in our study, we have found some differences in the number of items, which is due to the fact that are items that reveal unacceptable factor loadings in their different sub-scales. The difference between the internal and the external components of AI is less clear in the Portuguese AIMS-plus than in the original scales, which is consistent with other studies that are inconclusive in regards to this subdivision (Nasco \& Webb, 2006).

The differences that were found seem to be due to the fact that criterion validity is always culture-specific (Anastasi \& Urbina, 2000). Some studies also emphasize the idea that different cultures may have different selfstructures and processes, as well as different kinds of self-concept elements which impact upon their cognitions, emotions and motivations (Walker, Deng, \& Dieser, 2005). This suggests that different cultures may perceive their identity with some differences among the many similarities. One limitation of this study has to do with the fact that our sample is different from the one that was used by the original authors. The sample for the original scale's study was mostly composed by university-student athletes from intramural sports league programs, whereas the Portuguese sample originated from sports leagues and federations, including athletes with international representation and Olympic participation.

Culturally speaking - and much like in most European countries - sports are mostly practiced in clubs and registered athletes do not have as much representation within the university system as they do in the North America. This aspect may have contributed to the differences between Portuguese and North American people in the way they responded to some items, indicating that the process of identity formation may very well be influenced by situational motives or environmental circumstances (Nasco \& Webb, 2006).

A strong, positive and statistically significant correlation between the AIMS-plus (Cieslak, 2004) and the AIMS (Brewer \& Cornelius, 2001), which constitutes an indicator of concurrent validity, suggesting that both scales derive from concepts that are very similar to the AI concept. These findings establish the AIMS-plus as a adequate tool for researching, along with the AIMS. The results that were found in regards to the scale's factor invariance come to strengthen the previous idea.

The results obtained in this study support the idea that AI is a multi-dimensional construct, composed by five 
factors: exclusivity, social identity, self-identity, positive affectivity and negative affectivity.

Taking into account the strong correlation between the AIMS-plus and the AIMS, it is suggested that the AIMS-plus - which assesses for more dimensions (five) of the AI construct - be utilized in a practical context as a tool to support individual intervention with athletes on the part of those professionals working with sports and psychological issues that are related to athletic identity. The AIMS - presenting itself as a widely recognized research instrument with excellent psychometric properties and a short measure ( 7 items) - would be more indicated for research utilization, guaranteeing the success of the results thus far obtained.

Normative data for the AIMS-plus must be established in future research, in order to obtain national norms for the different athletic identity factors and for the overall scale level, taking into account gender, age-groups and competition level of the athletes. Further studies of the instrument's psychometric properties are, also, necessary.

In the future, it would be interesting to understand whether AI can be a good predictor of drop out in face of athletic failure circumstances. On the other hand, it would be important to identify which other psychological factors, such as the personality, could be at the root of athletic identify formation.

In conclusion, it can be said that this research suggests that the Portuguese version of the AIMS-plus has similar psychometric properties to the original version of the scale. We hope that such evidence may in the future stimulate further research on the concept of athletic identity, as well as its practical applications in the context of psychological intervention.

\section{References}

Anastasi, A., \& Ubina, S. (2000). Psychological testing ( $7^{\text {nd }}$ ed.). Upper Saddle River, NJ: Prentice Hall.

Anderson, C. (2004). Athletic Identity and its Relation to Exercise Behavior: Scale Development and Initial Validation. Journal of Sport and Exercise Psychology, 26, 39-56.

Anderson, C., \& Coleman, K. (2008). Adaption and validation of the athletic identity questionnaire for use with children. Journal of Physical Activity and Health, 5, 539-558.

Anderson, C., Louise, M., Zhang, H., Coleman, K., \& Chang, S. (2009). Contribution of athletic identity to child and adolescent physical activity. American Journal of Preventive Medicine, 37(3), 220-225.

Anderson, C., Louise, M., Zhang, H., Coleman, K., \& Chang, S. (2011). Ethnic, Gender, and BMI Differences in Athletic Identity in Children and Adolescents. Journal of Physical Activity and Health, 8, 200-209.

Anderson, C., Mâsse, L., \& Hergenroeder, A. (2007). Factor and construct validity of the athletic identity questionnaire for adolescents. Medicine Science and Sports Exercise, 39, 59-69.

Arbuckle, J. (2009). AMOS18 Reference guide (Version 18). Chicago, IL: Statistical Package for the Social Sciences.

Balague, G. (1999). Understanding identity, value, and meaning when working with elite athletes. The Sport Psychologist, $13,89-98$.
Brewer, B. (1993). Self-identity and specific vulnerability to depressed mood. Journal of Personality, 61, 343-364.

Brewer, B. W., Boin, P. D., \& Petitpas, A. J. (1993). Dimensions of athletic identity. Paper presented at the American Psychological Association Annual Conference, Toronto, Canada.

Brewer, B., \& Cornelius, A. (2001). Norms and factorial invariance of the Athletic Identity Measurement Scale (AIMS). Academic Athletic Journal, 16, 103-113.

Brewer, B., Cornelius, A., Stephan, Y., \& Van Raalte, J. (2010). Self-protective changes in athletic identity fallowing anterior cruciate ligament reconstruction. Psychology of Sport and Exercise, 11, 1-5.

Brewer, B., Van Raalte, J., \& Linder, D. (1993). Athletic identity: Hercules' muscles or Achilles heel? International Journal of Sport Psychology, 24, 237-254.

Brown, T. (2006). Confirmatory factor analysis for applied research. New York. The Guildford Press.

Browne, M., \& Cudeck, R. (1993). Alternative ways of assessing model fit. In K. A. Bollen \& J. S. Long (Eds.), Testing Structural Equation Models (pp. 136-162). Beverly Hills, CA: Sage.

Burke, P. (1991). Identity processes and social stress. American Sociological Review, 56, 836-849.

Byrne, B. (2010). Structural equation modeling with AMOS: Basic concepts, applications and programming $\left(2^{\text {nd }}\right)$. New York: Routledge.

Cabrita, T., Rosado, A., \& Malico, P. (2007). Em busca da identidade atlética: Validação portuguesa da escala da identidade atlética [In pursuit of athletic identity: Portuguese validation of athletic identity scale]. Paper presented at the CIPDE'07 International Conference of Sport and Exercise Psychology, Universidade do Minho, Braga, Portugal.

Carlson, M., \& Mulaik, S. A. (1993). Trait ratings from descriptions of behavior as mediated by components of meaning. Multivariate Behavioral Research, 28, 111-159.

Cieslak, T. (2004). Describing and measuring the athletic identity construct: Scale development and validation (Unpublished doctoral dissertation). Ohio State University, Columbus, $\mathrm{OH}$.

Cieslak, T., Fink, J., \& Pastore, D. (2005). Measuring the athletic identity construct: Scale development and validation. Journal of Sport \& Exercise Psychology, 27(Suppl.), S48.

Cornelius, A. (1995). The relationship between athletic identity, peer and faculty socialization, and college student development. Journal of College Student Development, 36, 560-573

Curry, T. J., \& Weaner, J. S. (1987). Sport identity salience, commitment, and the involvement of self in role: Measurement issues. Sociology of Sport Journal, 4, 280-288.

Davey, A. (2010). Statistical power analysis with missing data: A structural equation modeling approach. New York: Taylor and Francis Group.

Delgado, G., Stanford, D., \& Cieslak, T. (2005). Comparing the athletic identification of individuals participating in a division II intercollegiate athletic program [Abstract]. Journal of Sport and Exercise Psychology, 27(Suppl.), S54.

Fornell, C., \& Larcker, D. (1981). Evaluation structural equations models with unobservable variable and measurement error. Journal of Marketing Research, 18, 39-50.

Gerbin, D., \& Andersen, J. (1985). The effects of sampling error and model characteristics on parameter estimation for maximum likelihood confirmatory analyses. Multivariate Behavioral Research, 20, 255-271.

Groff, D., \& Zabriskie, R. (2006). An exploratory study of athletic identity among elite alpine skiers with physical disabilities: Issues of measurement and design. Journal of Sport Behavior 29(2), 126-141. 
Cabrita, T. M., Rosado, A. B., Leite, T. O., Sousa, P. M. (2014). Adaptation of the Athletic Identity Measurement Scale (AIMS-Plus) for the Portuguese Population.

Grove, J., Lavalle, D., \& Gordon, S. (1997). Coping with retirement from sport: The influence of athletic identity. Journal of Applied Sport Psychology, 9, 191-203.

Hair, J., Anderson, R., Tatham, R., \& Black, W. (2009). Multivariate data analysis ( $7^{\text {th }}$ ed.). Upper Saddle River, NJ: Prentice Hall.

Hale, B. D., James, B., \& Stambulova, N. (1999). Determining the dimensionality of athletic identity: A Herculean cross-cultural undertaking. International Journal of Sport Psychology, 30, 83-100.

Hambleton, R. (1994). Guidelines for adopting educational and psychological tests: A progress report. European Journal of Psychological Measurement, 10, 229-244.

Hambleton, R., \& Kanjee, A. (1995). Increasing the validity of cross-cultural assessments: Use of improved methods for test adaptations. European Journal of Psychological Assessment, 11, 147-157.

Horton, R., \& Mack, D. (2000). Athletic identity in marathon runners: Functional focus or dysfunctional commitment? Journal of Sport Behaviour, 32(2), 101-119.

Hurst, R., Hale, B., Smith, D., \& Collins, D. (2000). Exercise dependence, social physique anxiety, and social support in experienced and inexperienced bodybuilders and weightlifters. British Journal of Sports Medicine, 34(6), 431-435.

Joreskog, K. (1993). Testing structural equation models. In K. A. Bollen \& J. S. Long (Eds.), Testing structural equation models (pp. 294-316). Newbury Park, CA: Sage.

Jun, J. (2008). Bringing identity theory into leisure (Unpublished Doctoral Dissertation). Texas A\&M University, College Station, TX.

Kline, R. (2011). Principles and practices of structural equation modeling $\left(3^{\text {rd }}\right.$ ed.). New York: The Guilford Press.

Kollo, T. (2008). Multivariate skewness and kurtosis measures with an application in ICA. Journal of Multivariate Analyses, 99, 2328-2338.

Lamont-Mills, A., \& Christensen, S. (2006). Athletic identity and its relationship to sport participation levels. Journal of Science and Medicine in Sport, 9, 472-478.

Marsh, H. (1990). A multidimensional, hierarchical model of selfconcept: Theoretical andempirical justification. Educational Psychology Review, 2, 77-172.

Marsh, H. W., Balla, J. R., \& McDonald, R. P. (1988). Goodnessof-fit indices in confirmatory factor analysis: The effect of sample size. Psychological Bulletin, 102, 391-410.

Martin, J., Mushett, C., \& Eklund, R. (1994). Factor structure of the athletic identity measurement scale with adolescent swimmers with disabilities. Brazilian International Journal of Adapted Physical Education Research, 1(1), 87.

Martin, J., Mushett, C., \& Smith, K. (1995). Athletic identity and sport orientation of adolescent swimmers with disabilities Adapted Physical Activity Quarterly, 12(2), 113-123.

Mastean, R., Tusak, M., \& Faganel, M. (2006). Impact of identity on anxiety in athletes. Kinesiology, 38(2), 126-134.

Nasco, S., \& Webb, W. (2006). Toward an expanded measure of athletic identity: The inclusion of public and private dimensions. Journal of Sport \& Exercise Psychology, 28, 434-453.

Richard, T. (2007). Personal identity in adolescent football players: An explorative study. Halmstad, Sweden: School of Social and Health Sciences, Halmstad University.

Schmid, J., Adams, J., \& Cheng, D. (2009). Cardiac rehabilitation of a 77 year-old male runner: Consideration of the athlete, not the age. Baylor University Medical Center Proceedings, 22(1), 16-18.
Schumaker, R., \& Lomax, R. (2004). A beginner's guide to structural equation modeling ( $2^{\text {nd }} \mathrm{ed}$.). Mahwah, NJ: Psychology Press.

Shapiro, R., \& Martin, J. (2010). Athletic identity, affect, and peer relations in youth athletes with physical disabilities. Disability and Health Journal, 3(2), 79-85.

Smith, D., Hale, B., \& Collins, D. (1998). Measurement of exercise dependence in bodybuilders. Journal of Sports Medicine and Physical Fitness, 38, 66-74.

Stryker, S. (1980). Symbolic Interactionalism: A Social Structural Version. Menlo Park, CA: Benjamin Cummings.

Visek, A., Hurst, J., Maxwell, J., \& Watson, J., II. (2008). A cross-cultural psychometric evaluation of the athletic identity measurement scale. Journal of Applied Sport Psychology, 20(4), 473-480.

Walker, G., Deng, J., \& Dieser, R. (2005). Culture, self-construal, and leisure: Theory and practice. Journal of Leisure Research, 37(1), 77-99.

Webb, W., Nasco, S., Riley, S., \& Headrick, B. (1998). Athlete identity and reactions to retirement from sports. Journal of Sport Behavior, 21(3), 1-24.

Wiechman, S. A., \& Williams, J. (1997). Relationship of athletic identity to injury and mood disturbance. Journal of Sport Behaviour, 20, 199-210. 